\title{
Effects of pitch spatial references on players' positioning and physical performances during football small-sided games
}

Diogo Coutinho, Bruno Gonçalves, Bruno Travassos, Eduardo Abade, Del P. Wong \& Jaime Sampaio

To cite this article: Diogo Coutinho, Bruno Gonçalves, Bruno Travassos, Eduardo Abade, Del P. Wong \& Jaime Sampaio (2018): Effects of pitch spatial references on players' positioning and physical performances during football small-sided games, Journal of Sports Sciences, DOI: 10.1080/02640414.2018.1523671

To link to this article: https://doi.org/10.1080/02640414.2018.1523671

Published online: 11 Oct 2018.

Submit your article to this journal ¿

Џ Article views: 34

View Crossmark data ¿ 


\title{
Effects of pitch spatial references on players' positioning and physical performances during football small-sided games
}

\author{
Diogo Coutinho (1) a,b Bruno Gonçalves (1) ${ }^{\mathrm{a}, \mathrm{b}}$, Bruno Travassos (1) ${ }^{\mathrm{b}, \mathrm{c}}$, Eduardo Abade $\mathbb{1}^{\mathrm{b}, \mathrm{d}}$, Del P. Wong \\ and Jaime Sampaio (10)
}

\begin{abstract}
${ }^{a}$ Department of Sports Sciences, Exercise and Health, University of Trás-os-Montes and Alto Douro, Vila Real, Portugal; ${ }^{b}$ CIDESD - Research Center in Sports, Health Sciences and Human Development, Portugal; 'Department of Sports Sciences, University of Beira Interior, Covilhã, Portugal; dUniversity Institute of Maia, ISMAI, Maia, Portugal; 'Sport Science Research Center, Shandong Sport University, Jinan, China
\end{abstract}

\section{ABSTRACT}

The aim of this study was to identify the effects of adding spatial references during football small-sided games in youth players' tactical and physical performance. Twelve under-15 players performed a Gk + 6v6+ Gk game under two playing conditions: (i) without spatial references (CONTROL condition); (ii) with spatial references, by dividing equally the pitch into three corridors and three sectors (experimental situation, LINES). Players' positional data was used to compute time-motion and tactical-related variables. The results revealed that performance under LINES situation increased the regularity in the zones occupied $(\sim 14 \%$, Cohen's $d: 0.5 ; \pm 0.3 ; p=0.003)$ and in the distance between teammates' dyads $(\sim 19 \%, 0.9 ; \pm 0.2 ; p<0.001)$. Oppositely, LINES condition decreased the longitudinal synchronization of players' displacements $(0.4 ; \pm 0.2 ; p=0.002)$, players' average speed $(0.5 ; \pm 0.3 ; p=0.002)$ and distance covered at lower $(0.9 ; \pm 0.3 ; p<0.001)$ and moderate speed $(0.5 ; \pm 0.3 ; p<0.001)$. Adding spatial references seems to promote a more structured pattern of play and increase positional regularity. However, coaches should be aware that this constraint may decrease the synchronization between players. Overall, these findings may be generalized to most invasion team sports.
ARTICLE HISTORY

Accepted 8 June 2018

\section{KEYWORDS}

Positioning variables; GPS; synchronization; teamsports; task constraints

\section{Introduction}

Team sports performance consists in a continuous process of co-adaptation (Araujo \& Davids, 2016; Araújo, Davids, \& Hristovski, 2006; Davids, Glazier, Araujo, \& Bartlett, 2003), in which players establish spatial-temporal interactions with the environment to sustain the emergence of functional movement behaviours (Davids et al., 2003; Ric, Hristovski, Gonçalves, Torres, Sampaio, \& Torrents, 2016). Accordingly, successful performances have been linked to the interpersonal relations developed by teams in order to achieve goal-directed behaviours (Araujo \& Davids, 2016; Duarte et al., 2013; Fajen, Riley, \& Turvey, 2009; Gonçalves, Marcelino, Torres-Ronda, Torrents, \& Sampaio, 2016; Passos, Araújo, \& Davids, 2016; Travassos, Duarte, Vilar, Davids, \& Araujo, 2012). The level of this coordination depends on the players' ability to use environmental information, which in turn, will lead to the emergence of opportunities for action (Passos et al., 2016; Seifert, Button, \& Davids, 2013; Travassos et al., 2012). Players' positioning is based on how each individual exploit the environment information to support the emergence of functional movement behaviours (Seifert et al., 2013; Travassos et al., 2012). For example, research shows that players present higher regularity in movement behaviour as the number of opponents increase (4vs3, 4vs5 and 4vs7) during small-sided games (Gonçalves et al., 2016). Other sports have also found different movement behaviours patterns as result of the modification of the distance to the target or angular relationship in basketball (Esteves et al., 2015, 2015), the distance between defenders in rugby (Correia et al., 2012) or the presence of the look-up line in ice hockey (Vickers et al., 2017). These evidences highlight that different functional behaviours emerged as consequence of the manipulation of the environmental information. In this sense, adding or removing information during the training tasks is likely to stimulate different behavioural patterns.

Small-sided games (SSG) have become a widely-recognized training resource to develop the players' behaviour (Sampaio, Lago, Gonçalves, Macas, \& Leite, 2014; Travassos, Gonçalves, Marcelino, Monteiro, \& Sampaio, 2014). In fact, SSG allows to reproduce the kinematic, physical, physiological, technical and tactical demands of the competitive environments (Coutts, Rampinini, Marcora, Castagna, \& Impellizzeri, 2009; Davids, Araújo, Correia, \& Vilar, 2013). Accordingly, the SSG allow the manipulation of task constraints to induce different training responses according to the learning aim (Coutts et al., 2009; Davids et al., 2013; Sampaio et al., 2014; Travassos et al., 2012, 2014). Thus, the manipulation of task constraints has emerged as a relevant research topic (Travassos et al., 2012) in the search for understanding how their manipulations affect the players' behaviours (Gonçalves et al., 2017; Travassos et al., 2014). Under this scope, the available literature has analysed the effects of 
manipulating several variables on players' movement patterns during football SSG (Sampaio et al., 2014; Silva et al., 2014). These studies have shown that increasing the pitch size lead the players towards a more regular positioning and structured playing style (Silva et al., 2014). It has also been shown that uneven player numbers between teams and the game score influences cooperation and opposition behaviours. For instance, the teams become more compact when losing and when playing with fewer players than the opponent team (Sampaio et al., 2014). Another important contribution from the study of Sampaio et al. (2014) was the incorporation of physical performance according to the tactical requirements of the task. That is, players positioning is influenced by the interpersonal coordination tendencies that emerge from the interaction with teammates and the environment (Gonçalves et al., 2016; Passos et al., 2016). Thus, a better understanding of the physical demands may be possible if the strategies used by the players to be coordinated with teammates (e.g. trajectories and individual speed) are investigated (Sampaio et al., 2014; Travassos et al., 2012).

Apart from these manipulations, there have been some attempts to understand how different spatial references modifies the interpersonal coordination tendencies between players. For instance, the modification in the information available as a result of the target location in futsal (Vilar et al., 2014) and the number and dimension of goals available to score in football (Travassos et al., 2014), have shown to emerge different functional movement behaviours. More recently, Gonçalves et al. (2017) investigated how pitch area-restrictions affect the players' physical and tactical performance. For this purpose, it were tested three conditions: i) restricted-space, the pitch was divided into areas from where players were not allowed to move; ii) contiguous-spacing, players were allowed to move to a neighbouring area; iii) free-spacing, without movement restrictions. It was reported that limiting the space exploration detuned the players' movement synchronization with teammates and decreased physical and physiological performances. In this sense, the increase of information induced by the addition of the spatial references, may highlight different information and divert players' attention from the teammates positioning. Consequently, this modification in the available information is likely to affect the level of team synchronization. Possibly, players become more focused with their own positioning under the restricted-space condition by detuning their positioning with teammates movements. In fact, the available literature has shown that when new information emerges, players are able to narrow the opportunities for action by anticipating possible outcomes (Bruineberg, Kiverstein, \& Rietveld, 2016; Bruineberg \& Rietveld, 2014; Friston, 2010), leading to the emergence of goal-directed behaviours, (Davids et al., 2003; Seifert et al., 2013; Seifert, Komar, Araújo, \& Davids, 2016). This self-organizing behaviour results from the players' actions coupling with the environmental information (Araújo et al., 2006; Davids et al., 2003; Gibson, 1979; Seifert et al., 2013, 2016).

Although insightful information has been provided by the available literature about players' adaptation according to different spatial references (Gonçalves et al., 2017; Travassos et al., 2014; Vilar et al., 2014), research in this topic is still scarce. Furthermore, coaches usually add spatial references during SSG to amplify the players' breath of attention and perceived stimuli (Travassos et al.,
2014). For example, in a defensive organisation task, coaches may specify the penalty box as a spatial reference for the defenders to stay compact and aligned when the opponents are approaching their target. Evidences from the use of different spatial references in training drills have been found in different drills-based textbooks in football (Lennox, Rayfield, \& Steffen, 2006), rugby (Biscombe \& Drewett, 2010), basketball (Rose, 2012) and American football (Mallory, Nehlen, \& Association, 2005). However, taking into consideration that the presence of spatial references seems to induce different movement behaviours, further research is need to better understand how these spatial references regulate players' behaviour. Therefore, the aim of this study was to examine the effects of adding spatial references during football small-sided games in youth players' tactical and physical performance. In this report, we first hypothesized that adding spatial references modifies the spatial-temporal interactions between players. In this sense, the spatial references were used to analyse whether it could help, or not, the players to guide their behaviour during football SSG. By adding these references, it was expected that players increase their positional regularity. Our second hypothesis is that the spatial references may decrease the players activity profile.

\section{Methods}

\section{Participants}

Twelve youth football players (Age $=15.9 \pm 0.8 \mathrm{y}$; Height $=172.8 \pm 5.2 \mathrm{~cm}$; Mass $=59.5 \pm 5.2 \mathrm{~kg}$; Peak running speed $=23.3 \pm 2.8 \mathrm{~km} \cdot \mathrm{h}^{-1} ;$ Y Years of experience $=8.9 \pm 2.4$ years) participated in this study. All players were members of the same team and performed three training sessions per week (90 to 105 minutes per session) and played an official game during the weekend at a regional playing standard in a regular turf football field. Players had trained in the club for $5.0 \pm 2.6$ years and have 42 weeks of training a year. Two goalkeepers were part of the study but were excluded from the data analysis taking into consideration that their positioning is limited to a specific pitch location. As consequence, their game dynamics are different from the outfield players (Gonçalves et al., 2016). Coaches, players, and their parents, as well as the club, provided informed and written consent before the beginning of the study. All participants were notified that they could withdraw from the study at any time. The study protocol followed the guidelines stated in the Declaration of Helsinki and was approved by the Local Ethics Committee.

\section{Study design}

The study design was based on a repeated measure approach under two experimental conditions: (i) a control situation by playing without spatial references (CONTROL condition); (ii) experimental situation by playing with spatial references (reference lines) by dividing the pitch into three corridors and three sectors (LINES condition). For this purpose, the games were played using Gk+ 6vs6+ Gk SSG formats, as it provides the main team structure for the 11-a-side (1 goalkeeper, 2 defenders, 3 midfielders and 1 forward) and it is widely used in youth competitions (BarberoAlvarez et al., 2015). Additionally, it was previously shown that team's tactical performance is only relevant with, at least, a SSG 
format with a 4-a-side, where it is provided the main team structure (1 defender, two midfielders and 1 forward) (Aguiar, Gonçalves, Botelho, Lemmink, \& Sampaio, 2015).

\section{Procedures}

All players were tested during two sessions with one week apart. No familiarization session was performed, since the players were already familiarized with the conditions used in this study (this condition was performed four times in the previous month to data collection). Furthermore, training tasks using spatial references during players training routines were frequent. The order of each condition was set randomly. In both situations, the session started with a standardized 15-min warm-up based on running and a ball possession game (6-a-side without goals). Afterwards, the SSG condition was performed. In both SSG were played at the same time of day, to avoid effects of circadian rhythms on the results, and under sunny conditions $\left(23 \pm 6^{\circ}\right)$.

\section{Experimental task}

For the SSG, the head coach selected the twelve best players from the team according to his subjective evaluation of their technical, tactical and physical skills (Casamichana \& Castellano, 2010). Then, the players were divided into two balanced teams taking into account their playing positions (e.g. players who played near to the pitch lateral lines during 11-a-side matches, occupied positions near to the lateral corridors). Each team played two $\mathrm{Gk}+6 \mathrm{v} 6+\mathrm{Gk}$ on an $62 \times 43 \mathrm{~m}$ artificial turf pitch (length $x$ width; $\sim 200 \mathrm{~m}^{2}$ relative playing space per player). This pitch size have been used in SSG involving at least 7 players per team (Castellano, Puente, Echeazarra, Usabiaga, \& Casamichana, 2016), and using 7-a-side goals. Each team took part in the two conditions, CONTROL and LINES. For this last condition, ten flat markers were placed for each vertical and horizontal line, allowing to divide the pitch into three corridors and three sectors, having each section the same size (See Figure 1(a)). The pitch division was based on previous studies (Gonçalves et al., 2016), however different distance between zones were employed to allow to compare the players' movement regularity across the different zones. The SSG of each condition lasted for a total of 24-min including three bouts of 6 min interspersed with a 3-min passive recovery period. Before the SSG, the players were instructed to perform the task according their own playing positional role, and this was keep constant in both testing days. That is, in both sessions, the players belong to the same team and played in the same position. Several balls were placed around the field to ensure its replacement as fast as possible, decreasing the time that the ball was out of play. No coach feedback or encouragement was allowed a) Pitch Without Reference Lines (CONTROL)

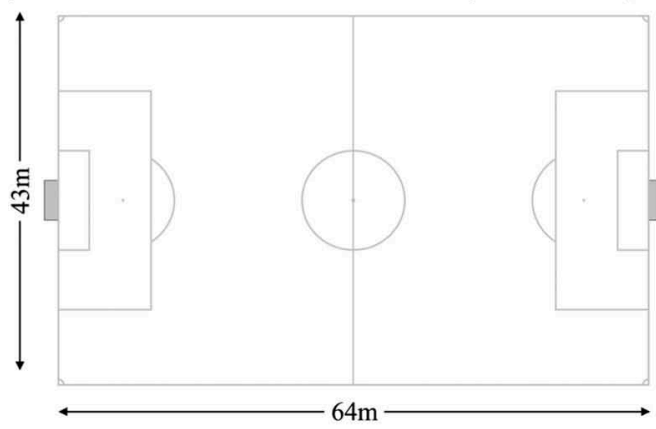

Pitch With Reference Lines (LINES)

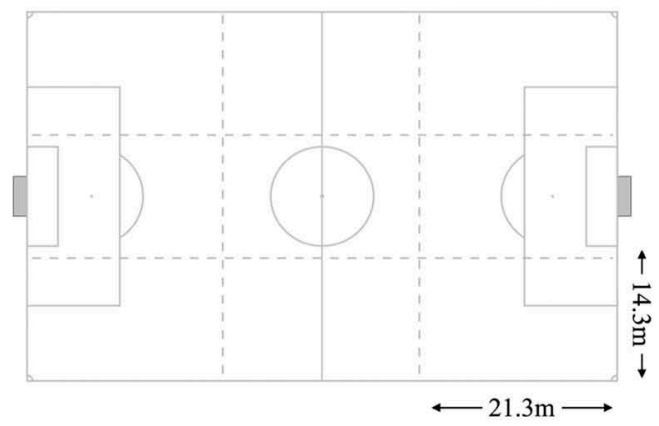

Players Spatial Movement Regularity

b) Pitch Without Reference Lines (CONTROL)

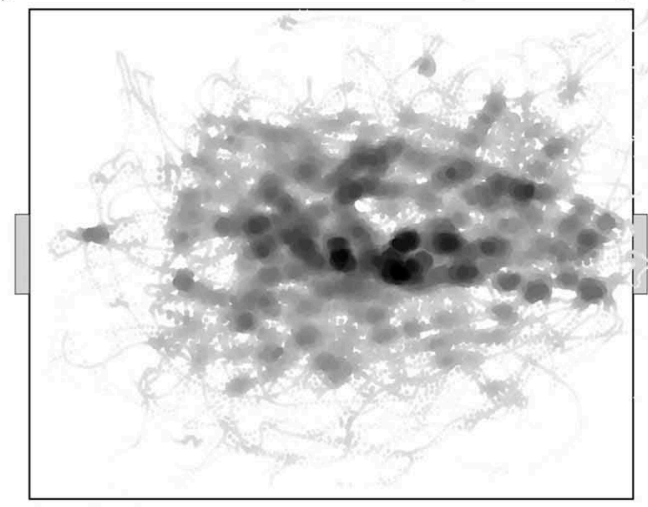

Stretch Index $=8.76 \pm 0.98$

Regularity in Stretch Index (Approximate Entropy) $=0.17 \pm 0.07$

Regularity in Zones Occupied (Approximate Entropy) $=0.044 \pm 0.011$
Pitch With Reference Lines (LINES)

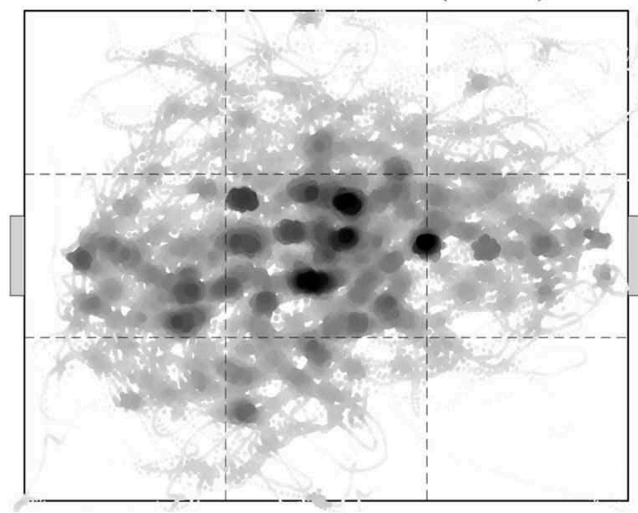

Stretch Index $=9.03 \pm 1.12$

Regularity in Stretch Index (Approximate Entropy) $=0.14 \pm 0.05$

Regularity in Zones Occupied (Approximate Entropy) $=0.038 \pm 0.007$

Figure 1. (a) Representation of SSG task conditions: without (left figure - CONTROL) and with spatial references (right figure - LINES); (b) Players spatial movement regularity example for one bout of the SSG conditions. Left figure represents the SSG without spatial references (CONTROL), while the right figure represents the SSG with spatial references (LINES). Mean \pm sd values were reported for each SSG condition. ApEn = approximate entropy. 
during the conditions. The players were encouraged to hydrate with water before the SSG and also in-between the bouts. Both sessions started at the same time of the day and were completed within the same duration (90 minutes). The repeated measures design from this study implied that each participant responses were measured in six different SSG bouts.

\section{Data collection}

\section{Physical and positional data}

Positional data and the distance covered during SSG were gathered using $5 \mathrm{~Hz}$ global positioning system (GPS) units (SPI-PRO, GPSports, Canberra, ACT, Australia). The players' latitude and longitude coordinates obtained through games units were exported and computed using appropriate routines in Matlab ${ }^{\circledR}$ (MathWorks, Inc., Massachusetts, USA). Additionally, missed data were re-sampled and the tracking error noise was reduced by smoothing the data based on a $3 \mathrm{~Hz}$ Butterworth low pass filter (see Folgado, Duarte, Fernandes, and Sampaio (2014) to data correction guidelines).

The dynamic positional data of the players were used to determine the team stretch index per minute (Travassos et al., 2014), the distance between teammates' dyads ( $n=15$ dyads per team) and the magnitude of the variability in the distance between players', expressed by the coefficient of variation (CV) (Gonçalves et al., 2017). The approximate entropy (ApEn) technique was applied to analyse the structure of variability expresses in regularity of the time series corresponding to the stretch index and to the distance between players. The ApEn outcome ranges from 0 to 2 , in which lower values correspond to more repeatable patterns. For example, values closer to 0 in the distance between dyads, means that the players dyads tend to stay at the same distance in a more repeatable fashion. The imputed values used to compute were 2 to vector length $(\mathrm{m})$ and $0.2^{*}$ std to the tolerance (r) (Yentes et al., 2013). The ApEn variable was also applied to the players' zones occupied (Regularity in Zones Occupied). For this purpose, the pitch was divided into 9 zones (formed by the interceptions of pitch lines) and the players' displacements during the SSG were assigned to the corresponding pitch zone. Then, in the time series corresponding to the movements in the zones occupied by the players was applied the ApEn technique. The intra-team coordination tendencies were assessed based on the time that teammates dyads spent synchronized in both longitudinal and lateral directions. These two last variables were calculated with the Hilbert transform (Palut \& Zanone, 2005) and applied for all possible dyads for the six outfield teammates (possible 15 dyads). The near-inphase synchronization of each dyad was quantified by the percentage of time spent between $-30^{\circ}$ to $30^{\circ}$ bin (near-in-phase mode of coordination) (Folgado et al., 2014).

The total distance covered was recorded and three ratios were quantified to relate the distance covered at high to very high (Higher Ratio: above $16 \mathrm{~km} / \mathrm{h}$ ), moderate (Moderate Ratio: $10.0-15.9 \mathrm{~km} / \mathrm{h}$ ) and low intensity (Lower Ratio: $7.0-9.9 \mathrm{~km} / \mathrm{h}$ ) with distance covered at very low intensities $(0.0-6.9 \mathrm{~km} / \mathrm{h})$ normalized for each $100 \mathrm{~m}$ to allow comparisons (Abade, Gonçalves, Leite, \& Sampaio, 2014). Also, the players' average speed displacements $(\mathrm{km} / \mathrm{h})$ was presented.

\section{Statistical analysis}

A repeated measures $t$-test was used to compare the differences in the tactical and physical performances according to the CONTROL and to the LINES conditions. The statistical analysis was carried in SPSS Software ${ }^{\circledR}$ and significance was maintained at $5 \%$. Complementary, magnitude-based inferences and precision of estimation were applied (Batterham \& Hopkins, 2006; Wilkinson \& Winter, 2018). Prior to the task conditions comparisons, all processed variables were logtransformed to reduce the non-uniformity of error. A descriptive analysis was reported as mean and standard deviations for all the considered variables (the mean shown is the backtransformed mean of the log transform). Thus, the comparisons among game conditions (CONTROL vs. LINES) were measured using standardized mean differences with $90 \%$ confidence intervals (Batterham \& Hopkins, 2006; Hopkins, Marshall, Batterham, \& Hanin, 2009; Wilkinson \& Winter, 2018). Thresholds for effect size statistics were: $<0.2$, trivial; 0.6 , small; 1.20 , moderate; 2.0 , large; and > 2.0, very large (Hopkins et al., 2009). Differences in group means were expressed in percentage units with $90 \%$ confidence limits (CL). Smallest worthwhile differences were assessed using the standardized units multiplied by 0.2 . Uncertainty in the true effects of the conditions were evaluated through nonclinical magnitude-based inferences. Magnitudes of clear effects were considered as the following scale: $<0.5 \%$, most unlikely; $0.5-5 \%$, very unlikely; $5-25 \%$, unlikely; 25 to $75 \%$, possibly; $75 \%$ to $95 \%$, likely; $95 \%$ to $99 \%$, very likely; > $99 \%$, most likely (Hopkins et al., 2009).

\section{Results}

Figure 1(b) presents the results for the stretch index, the approximate entropy from the stretch index and regularity in zones occupied between the CONTROL and LINES conditions. The results from the stretch index, despite no significant differences, revealed a small increase in the LINES scenario compared with the CONTROL condition (mean difference; $\pm 90 \%$ confidence limits: $2.9 ; \pm 4.5 \%$, possibly). Also, no significant differences were found between conditions in the approximate entropy values of the stretch index (lower approximate entropy values means more regular movement patterns). Nevertheless, the results showed a small decrease in approximate entropy values of the stretch index $(-15.4 ; \pm 14.8 \%$, likely) during the LINES condition compared to the CONTROL condition. In addition, small decreases in approximate entropy values of the occupied zones $(-14.3 ; \pm 9.3 \%$, very likely; $p=0.003$ ) was found during the LINES compared to the CONTROL.

Table 1 and Figure 2 presents the results from the comparison between CONTROL vs LINES for the positional and physical variables. In the LINES scenario there was a small increase in the coefficient of variation in the distance between the dyads $(12.9 ; \pm 3.8 \%$, most likely; $p<0.001)$ compared to the CONTROL. In contrast, the LINES condition presented a moderate decrease in the approximate entropy values in the distance between dyads $(-19.1 ; \pm 14.8 \%$, possibly; $p<0.001)$ compared to the CONTROL scenario. There was a small 
Table 1. Descriptive and statistical analysis for positional and physical variables according to SSG conditions.

\begin{tabular}{|c|c|c|c|c|c|c|}
\hline \multirow[b]{2}{*}{ Variables } & & \multicolumn{2}{|c|}{ Condition $($ mean \pm SD) } & \multirow{2}{*}{$\begin{array}{l}\text { Difference in Means } \\
\text { (\%; } \pm 90 \% \text { Confidence limits) } \\
\text { Uncertainly in true differences }\end{array}$} & \multirow[b]{2}{*}{$t$} & \multirow[b]{2}{*}{$p$} \\
\hline & & Control & Lines & & & \\
\hline \multirow[t]{5}{*}{ Positional Variables } & Stretch Index (meters) & $8.76 \pm 0.98$ & $9.03 \pm 1.12$ & $2.9 ; \pm 4.5$, Possibly Increase & -1.121 & 0.270 \\
\hline & Stretch Index (Approximate entropy) & $0.17 \pm 0.07$ & $0.14 \pm 0.05$ & $-15.4 ; \pm 14.8$, Likely Decrease & 1.912 & 0.064 \\
\hline & Distance between Dyads (coefficient of variation) & $0.42 \pm 0.08$ & $0.48 \pm 0.10$ & $12.9 ; \pm 3.8$, Most Likely Increase & -6.178 & $<0.001$ \\
\hline & Distance between Dyads (Approximate entropy) & $0.18 \pm 0.04$ & $0.15 \pm 0.03$ & $-19.1 ; \pm 3.6$, Most Likely Decrease & 8.047 & $<0.001$ \\
\hline & Regularity Zones Occupied (Approximate entropy) & $0.038 \pm 0.007$ & $0.044 \pm 0.011$ & $-14.3 ; \pm 9.3$, Very Likely Decrease & -3.167 & 0.003 \\
\hline \multirow[t]{4}{*}{ Physical Variables } & Average Speed (meters per second) & $24.19 \pm 3.34$ & $22.53 \pm 2.68$ & $-6.6 ; \pm 3.5$, Very Likely Decrease & 3.355 & 0.002 \\
\hline & High Ratio (meters) & $25.23 \pm 16.32$ & $28.24 \pm 16.01$ & $17.1 ; \pm 23.8$, Possibly Increase & -1.075 & 0.290 \\
\hline & Moderate Ratio (meters) & $96.56 \pm 43.37$ & $74.58 \pm 25.46$ & $-19.3 ; \pm 10.0$, Very Likely Decrease & 3.479 & 0.001 \\
\hline & Low Ratio (meters) & $166.06 \pm 23.11$ & $147.03 \pm 18.07$ & $-11.3 ; \pm 2.9$, Most Likely Decrease & 6.068 & $<0.001$ \\
\hline
\end{tabular}

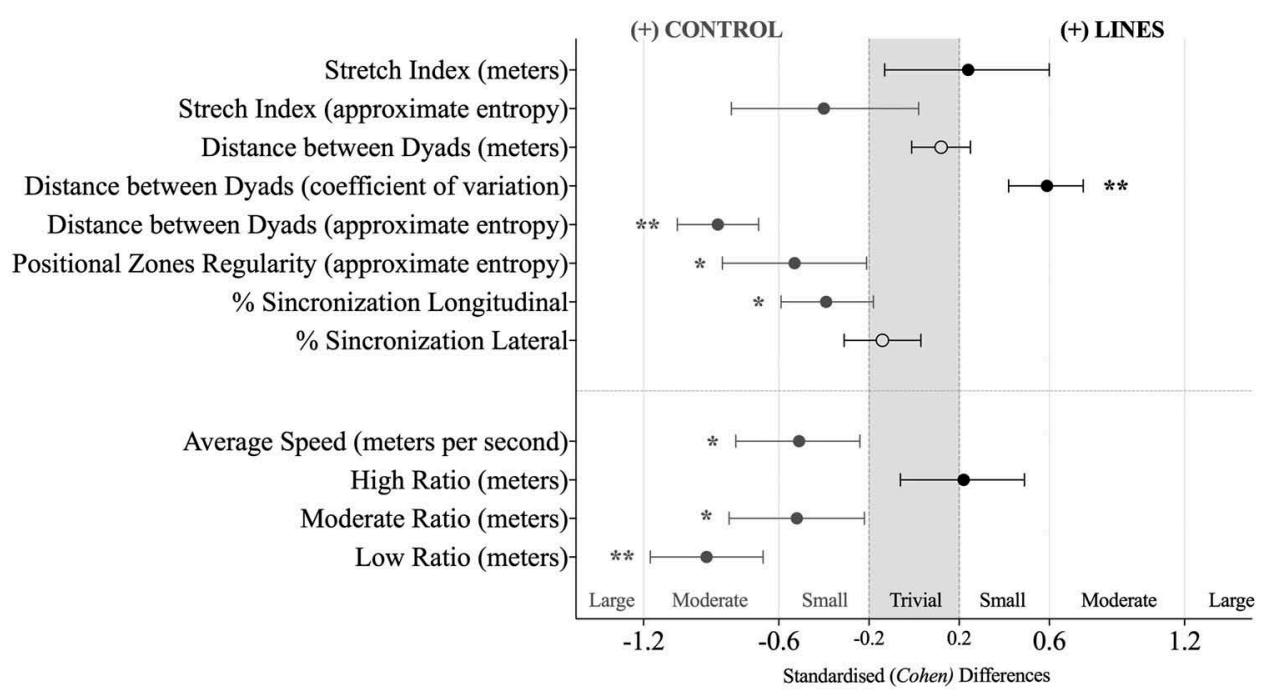

Figure 2. Standardized (Cohen) differences in positional and physical variables according to SSG condition (control, CONTROL Vs experimental, LINES). Error bars indicate uncertainty in the true mean changes with $90 \%$ confidence intervals. ${ }^{*} p<0.01 ;{ }^{* *} p<0.001$.

decrease in the percentage of time that players spent synchronized in the longitudinal displacements $(-5.6 ; \pm 2.9 \%$, likely; $p=0.002)$ during the LINES compared with the CONTROL condition.

From the physical performance, there was a small decrease in the average speed $(-6.6 ; \pm 3.5 \%$, very likely; $p=0.002)$ during the LINES compared to the CONTROL condition. Also, a moderate decrease in the low ratio $(-11.3 ; \pm 2.9 \%$, most likely; $p<0.001)$ and a small decrease in the moderate ratio $(-19.3$; $\pm 10.0 \%$, very likely; $p<0.001$ ) during the LINES compared to the CONTROL were depicted.

\section{Discussion}

This study aimed to identify the effects of adding spatial references in the players' tactical and physical behaviour during football SSG. Overall, adding the spatial references induced higher movement regularity (i.e., lower approximate entropy values) and increased the variability in the distance between dyads. On the opposite, there was a decrease in the levels of team synchronization, as well as, in both the average speed and distance covered at different speeds, when the spatial references were added.
The players positioning is a consequence from the perceived opportunities for action and the way of how individuals make use of the available information (Fajen et al., 2009; Passos et al., 2016). Thus, it is possible that the use of spatial references modified the information that sustained the players' behaviours. In fact, the decreases in dyadic synchronizations with the references lines, mainly for the longitudinal displacements, seems to confirm this evidence. Overall, it seems that when spatial references are added to a SSG, players become more attuned to their positioning according to these references than with teammates (Silva et al., 2014). Additionally, the results found in the approximate entropy values seems also to support these findings. That is, lower approximate entropy variables values (distance between dyads and regularity in zones occupied) were found in the pitch with spatial references (LINES). From practical application, lower values represent high regularity in observed variables and as consequence, more regular positioning of the players in this condition. For example, the approximate entropy results from the regularity in the occupied zones revealed that players are likely to move across zones in a more regular pattern (similar movements) in the pitch with spatial references. These results provide important novel information regardless how the players seem to co-adapt their 
behaviour according to different spatial references, such as the presence of reference lines. Coaches should be aware that adding spatial references increase the stability in players positioning but detune the players' synchronization within teammates.

Interestingly, no differences on the distance between players were found in this study, suggesting that the players seek to maintain their structural stability even with the manipulation in the task constraint. However, it also seems that to be able to maintain this stability during the LINES condition, the players' may have to increase the variability in their distance. That is, during the LINES condition it was found lower longitudinal synchronization and higher regularity, therefore, increasing the variability in the distance between players' may have emerged as a functional behaviour to maintain the team stability. In fact, the variability have been considered as essential to face the perturbations that emerge from the dynamic performance environment (Davids et al., 2003; Seifert et al., 2013).

A better understanding of the players' performance may be achieved when the physical and tactical are analysed together, once players' movement behaviour is influenced by how they perceive the information and couple their decisions with the teammates actions (Folgado et al., 2014; Gonçalves et al., 2016). In this sense, the lower average speed and distance covered at low and moderate speeds found in the pitch with reference lines (LINES) may be linked with the higher movement regularity. In turn, during the CONTROL condition, the players have to move in order to maintain the team synchronization (Gonçalves et al., 2017), which may justify the increase in the distance covered at low and moderate speeds. This complementary analysis between the positional and timemotion variables may also provide insightful information to coaches. For instance, coaches should be aware of the physical requirements that different tactical tasks might have on players to properly plan the short- and mid-term schedules.

Whilst this study adds novel and important findings regarding the effects of the spatial references on the players' movement behaviour, some limitations should be acknowledged. Firstly, although the use of spatial references was familiar for the players, based on their usual application during the training routines, different results may been found with larger sample sizes and participants unfamiliar with the tasks. Furthermore, it is also possible that different results may emerge with older players and with players of different expertise, since they interact differently with the environmental information (Seifert et al., 2016).

\section{Practical applications}

The spatial references were shown to increase the players' movement regularity. In this sense, adding spatial references may emerge as an alternative solution to develop the players specific positioning movements behaviours and to manage the physical performance during football SSG. Also, these results may suggest the use of spatial references to develop the team defensive organization, where a more structured pattern of play may be required. Contrarily, the increase in the players' movement synchronization without spatial references suggest that they are more coupled with teammates. Therefore, game-bases situations without reference lines may be used to train the team offensive movement patterns, whereas a lower structured playing style is intended to create instability in the opponents' defence. These findings highlight that different movement behaviours emerged as result of the spatial references.

\section{Conclusions}

The results from this study show that different self-organized behaviours emerged during football SSG as consequence of the spatial references. Accordingly, higher movement regularity was found in the LINES scenario, possible as consequence of a modification in the information induced by the reference lines (more space related). In contrast, higher movement synchronization was found during the CONTROL condition, suggesting that the players' guide their behaviour on teammates positioning when no spatial references are available. In addition, to maintain this synchrony, the players' have to move, which justify the higher average speed and distance covered at low and moderate speeds found in the CONTROL condition. Overall, these results provide insightful information that team sport coaches should acknowledge when design training tasks aiming to develop players' tactical behaviour.

\section{Acknowledgments}

This work was supported by the Portuguese Foundation for Science and Technology (FCT, Portugal) through a Doctoral grant endorsed to the first author (SFRH/BD/105081/2014) under the Human Potential Operating Program (POPH). Project NanoSTIMA: Macro-to-Nano Human Sensing: Towards Integrated Multimodal Health Monitoring and Analytics, NORTE01-0145-FEDER-000016, Fundo Europeu de Desenvolvimento Regional (FEDER) - NORTE 2020.

\section{Disclosure statement}

No potential conflict of interest was reported by the authors.

\section{Funding}

This work was supported by the Fundação para a Ciência e a Tecnologia [SFRH/BD/105081/2014];Fundo Europeu de Desenvolvimento Regional [NORTE-01-0145-FEDER-000026];

\section{ORCID}

Diogo Coutinho (D) http://orcid.org/0000-0001-6605-9505 Bruno Gonçalves (D) http://orcid.org/0000-0001-7874-4104 Bruno Travassos (D) http://orcid.org/0000-0002-2165-2687 Eduardo Abade (D) http://orcid.org/0000-0002-4766-896X Jaime Sampaio (D) http://orcid.org/0000-0003-2335-9991

\section{References}

Abade, E. A., Gonçalves, B. V., Leite, N. M., \& Sampaio, J. E. (2014). Timemotion and physiological profile of football training sessions performed by under-15, under-17 and under-19 elite Portuguese players. International Journal of Sports Physiology and Performance, 9(3), 463-470. 
Aguiar, M., Gonçalves, B., Botelho, G., Lemmink, K., \& Sampaio, J. (2015). Footballers' movement behaviour during 2-, 3-, 4- and 5-a-side smallsided games. Journal of Sports Sciences, 33(12), 1259-1266.

Araujo, D., \& Davids, K. (2016). Team synergies in sport: Theory and measures. Frontiers in Psychology, 7, 1449.

Araújo, D., Davids, K., \& Hristovski, R. (2006). The ecological dynamics of decision making in sport. Psychology of Sport and Exercise, 7(6), 653-676.

Barbero-Alvarez, J. C., Lopez, M. G., Castagna, C., Barbero-Alvarez, V., Romero, D. V., Blanchfield, A. W., \& Nakamura, F. Y. (2015). Game demands of 7-A-side soccer in young players. Journal of Strength and Conditioning Research / National Strength \& Conditioning Association. doi:10.1519/jsc.0000000000001143

Batterham, A. M., \& Hopkins, W. G. (2006). Making meaningful inferences about magnitudes. International Journal of Sports Physiology and Performance, 1(1), 50-57.

Biscombe, T., \& Drewett, P. (2010). Rugby: Steps to success. United States, Human Kinetics.

Bruineberg, J., Kiverstein, J., \& Rietveld, E. (2016). The anticipating brain is not a scientist: The free-energy principle from an ecological-enactive perspective. Synthese. doi:10.1007/s11229-016-1239-1

Bruineberg, J., \& Rietveld, E. (2014). Self-organization, free energy minimization, and optimal grip on a field of affordances. Frontiers in Human Neuroscience, 8, 599.

Casamichana, D., \& Castellano, J. (2010). Time-motion, heart rate, perceptual and motor behaviour demands in small-sides soccer games: Effects of pitch size. Journal of Sports Sciences, 28(14), 1615-1623.

Castellano, J., Puente, A., Echeazarra, I., Usabiaga, O., \& Casamichana, D. (2016). Number of players and relative pitch area per player: Comparing their influence on heart rate and physical demands in under-12 and under-13 football players. PLOS ONE, 11(1), e0127505.

Correia, V., Araújo, D., Duarte, R., Travassos, B., Passos, P., \& Davids, K. (2012). Changes in practice task constraints shape decision-making behaviours of team games players. Journal of Science and Medicine in Sport, 15(3), 244-249.

Coutts, A. J., Rampinini, E., Marcora, S. M., Castagna, C., \& Impellizzeri, F. M. (2009). Heart rate and blood lactate correlates of perceived exertion during small-sided soccer games. Journal of Science and Medicine in Sport, 12(1), 79-84.

Davids, K., Araújo, D., Correia, V., \& Vilar, L. (2013). How small-sided and conditioned games enhance acquisition of movement and decisionmaking skills. Exercise and Sport Sciences Reviews, 41(3), 154-161.

Davids, K., Glazier, P., Araujo, D., \& Bartlett, R. (2003). Movement systems as dynamical systems - The functional role of variability and its implications for sports medicine. Sports Medicine, 33(4), 245-260.

Duarte, R., Araujo, D., Correia, V., Davids, K., Marques, P., \& Richardson, M. J. (2013). Competing together: Assessing the dynamics of team-team and player-team synchrony in professional association football. Human Movement Science, 32(4), 555-566.

Esteves, P. T., Araújo, D., Vilar, L., Travassos, B., Davids, K., \& Esteves, C. (2015). Angular relationships regulate coordination tendencies of performers in attacker-defender dyads in team sports. Human Movement Science, 40, 264-272.

Esteves, P. T., Silva, P., Vilar, L., Travassos, B., Duarte, R., Arede, J., \& Sampaio, J. (2015). Space occupation near the basket shapes collective behaviours in youth basketball. Journal of Sports Sciences, 1-7. doi:10.1080/02640414.2015.1122825

Fajen, B. R., Riley, M. A., \& Turvey, M. T. (2009). Information, affordances, and the control of action in sport. International Journal of Sport Psychology, 40(1), 79.

Folgado, H., Duarte, R., Fernandes, O., \& Sampaio, J. (2014). Competing with lower level opponents decreases intra-team movement synchronization and time-motion demands during pre-season soccer matches. PLoS One, 9(5), e97145.
Friston, K. (2010). The free-energy principle: A unified brain theory? Nature Reviews. Neuroscience, 11(2), 127-138. http://www.nature.com/nrn/jour nal/v11/n2/suppinfo/nrn2787_S1.html

Gibson, J. J. (1979). The ecological approach to visual perception. Boston: Houghton Mifflin.

Gonçalves, B., Esteves, P., Folgado, H., Ric, A., Torrents, C., \& Sampaio, J. (2017). Effects of pitch area-restrictions on tactical behavior, physical and physiological performances in soccer large-sided games. Journal of Strength \& Conditioning Research, 31(9), 2398-2408. doi:10.1519/ JSC. 0000000000001700

Gonçalves, B., Marcelino, R., Torres-Ronda, L., Torrents, C., \& Sampaio, J. (2016). Effects of emphasising opposition and cooperation on collective movement behaviour during football small-sided games. Journal of Sports Sciences, 34(14), 1346-1354.

Hopkins, W. G., Marshall, S. W., Batterham, A. M., \& Hanin, J. (2009). Progressive statistics for studies in sports medicine and exercise science. Medicine \& Science in Sports \& Exercise, 41(1), 3-13.

Lennox, J. W., Rayfield, J., \& Steffen, B. (2006). Soccer skills and drills. United States, Human Kinetics.

Mallory, B., Nehlen, D., \& Association, A. F. C. (2005). Complete guide to special teams. United States, Human Kinetics.

Palut, Y., \& Zanone, P. G. (2005). A dynamical analysis of tennis: Concepts and data. Journal of Sports Sciences, 23(10), 1021-1032.

Passos, P., Araújo, D., \& Davids, K. (2016). Competitiveness and the process of co-adaptation in team sport performance. Frontiers in Psychology, 7, 1562.

Ric, A., Hristovski, R., Gonçalves, B., Torres, L., Sampaio, J., \& Torrents, C. (2016). Timescales for exploratory tactical behaviour in football small-sided games. Journal of Sports Sciences. doi:10.1080/02640414.2015.1136068

Rose, L. (2012). Winning basketball fundamentals. United States, Human Kinetics 1.

Sampaio, J., Lago, C., Gonçalves, B., Macas, V. M., \& Leite, N. (2014). Effects of pacing, status and unbalance in time motion variables, heart rate and tactical behaviour when playing 5 -a-side football small-sided games. Journal of Science and Medicine in Sport, 17(2), 229-233.

Seifert, L., Button, C., \& Davids, K. (2013). Key properties of expert movement systems in sport: An ecological dynamics perspective. Sports Medicine, 43(3), 167-178.

Seifert, L., Komar, J., Araújo, D., \& Davids, K. (2016). Neurobiological degeneracy: A key property for functional adaptations of perception and action to constraints. Neuroscience and Biobehavioral Reviews, 69, 159-165.

Silva, P., Aguiar, P., Duarte, R., Davids, K., Araújo, D., \& Garganta, J. (2014). Effects of pitch size and skill level on tactical behaviours of association football players during small-sided and conditioned games. International Journal of Sports Science \& Coaching, 9(5), 993-1006.

Travassos, B., Duarte, R., Vilar, L., Davids, K., \& Araujo, D. (2012). Practice task design in team sports: Representativeness enhanced by increasing opportunities for action. Journal of Sports Sciences, 30(13), 1447-1454.

Travassos, B., Gonçalves, B., Marcelino, R., Monteiro, R., \& Sampaio, J. (2014). How perceiving additional targets modifies teams' tactical behavior during football small-sided games. Human Movement Science, 38, 241-250.

Vickers, J. N., Causer, J., Stuart, M., Little, E., Dukelow, S., Lavangie, M., .. Emery, C. (2017). Effect of the look-up line on the gaze and head orientation of elite ice hockey players. European Journal of Sport Science, 17(1), 109-117.

Vilar, L., Araujo, D., Davids, K., Travassos, B., Duarte, R., \& Parreira, J. (2014). Interpersonal coordination tendencies supporting the creation/prevention of goal scoring opportunities in futsal. European Journal of Sport Science, 14(1), 28-35.

Wilkinson, M., \& Winter, E. M. (2018). Estimation versus falsification approaches in sport and exercise science. Journal of Sports Sciences, 1-2. doi:10.1080/02640414.2018.1479116

Yentes, J. M., Hunt, N., Schmid, K. K., Kaipust, J. P., McGrath, D., \& Stergiou, N. (2013). The appropriate use of approximate entropy and sample entropy with short data sets. Annals of Biomedical Engineering, 41(2), 349-365. 